\title{
ASTHMA IS MOSTLY A CLINICAL DIAGNOSIS!
}

Asthma is a substantial health problem worldwide, with high and increasing prevalence rates in many countries. ${ }^{1,2,3}$ Reports from the Western World show marked increase in the prevalence of asthma. ${ }^{1,3}$ It is indeed one of the few diseases to be increasing in prevalence. Various factors causing imbalance between the Th1 and the Th2 immune responses have been proposed as responsible for increasing prevalence of asthma. ${ }^{4,5}$ Foetal programming by the mother, including maternal smoking, and prenatal exposure to allergen, reduction in rates of infection during childhood (hygiene hypothesis), decreasing helminthes infection, indoor allergen exposure (particularly house dust mite and cat) particularly during the first 2-3 years, decreasing breastfeeding, including early exposure to foreign proteins, exposure to parental, especially maternal, smoking in early childhood, high salt diet and 'junk food', reduced antioxidant intake, air pollution etc have been proposed as increasing the risk of asthma. ${ }^{3-5}$ The increase prevalence of asthma seems to be associated with a westernized lifestyle or changing from rural to urban living possibly related to increase individual and population susceptibility. A more toxic environment and a more susceptible population both seem to play role.

Chronic obstructive pulmonary disease (COPD) is common in Nepal. ${ }^{6-8}$ But all that wheezes is not COPD. In COPD, indeed in any cause of wheeze, smoking cessation is obviously important. Otherwise from therapeutic point of view, asthma is more important to consider than COPD in patients with wheeze. But in a survey of junior doctors in Nepal about the use of the term COPD, overall more than $60 \%$ of participants included asthma under COPD. ${ }^{9}$ The reports of under-use of inhaled steroids in asthmatic patients from different parts of the world, especially the USA and Canada, indeed also support the presence of confusion among physicians globally about the term COPD. ${ }^{10-12}$ In another study conducted in the central hospital in Nepal, out of 104 consecutive presumed COPD patients, about $85 \%$ were smokers, more than $50 \%$ showed airway reversibility, i.e. they had asthma, rather than COPD. ${ }^{13}$

How do we diagnose asthma? It is important to realize that for all practical purpose asthma is mostly diagnosed clinically in our situation. Diagnosis with the help of spirometry or peak flow meter may not be possible in most of the situation. Undergraduates may say by rote and postgraduates may feel pride to discuss the various reversibility tests to diagnose asthma. But they may remain 'nice to know things' in most of our set up! Patients should not be diagnosed or lumped as COPD, just because spirometry or peak flow meter is not available. Variation in symptoms without obvious precipitating causes like acute severe bronchitis, pneumonia, pnuemothorax etc points towards the diagnosis of asthma rather than COPD. In hospital set up, virtually immobile, breathless patients walking freely a few days after getting corticosteroid may be one such example. In out-door set up, day-to-day, weeks-toweeks or months-to-months variation in mobility of patients should specifically be enquired into. Since how long the patient had not gone out of their house? Did the patient go to their relatives in the last festivals like 'Dasain'? If a severely breathless person had been moving freely a few days or months back, the diagnosis favours asthma rather than COPD. Variation of mobility of patients is especially a helpful pointer towards the diagnosis of asthma. Asking the symptoms directly alone may not clarify the situation, as the 'unsophisticated' patients may not express it properly. And of course, while making clinical assessment, history of allergic rhinitis may be a helpful pointer towards the diagnosis of asthma.

A few words need emphasis about the relation of smoking and breathless patients. COPD is known to occur due to indoor air pollution even in the absence of smoking. But the absence of smoking should always make cautious to accept the diagnosis of COPD easily. On the other hand, presence of smoking alone does not immediately point towards the diagnosis of COPD. 
Smoking is quite common in our country, particularly in the rural set up. So its presence alone should not lead one to jump to the conclusion of COPD. A breathless patient with mitral stenosis may be smoking; it does not prove the diagnosis of COPD. In a study of patients with chronic cor-pulmonale presenting to hospital, 4 out of 46 (almost 10\%) had mitral valvular disease, including mitral stenosis. ${ }^{14}$

Age is similarly another factor to remember. The prevalence of COPD peaks in the seventh and eighth decades. ${ }^{15}$ But in our set up, COPD is frequently diagnosed even in the third or fourth decades. Quite a number of asthma patients may be getting included under the diagnosis of COPD. Asthma may occur at any age, even in $90 \mathrm{~s}$. Though almost $50 \%$ of patients have onset of asthma before the age of 10 years, about $25 \%$ have onset after age $40 .{ }^{16}$ Thus, one cannot jump to any conclusion just by the age of patients and one particularly needs to be cautious before labeling any patients of third to fifth decade as COPD.

It is easy to label breathless patients as COPD. But COPD is basically a obstructive chronic bronchitis and emphysema (OCBE) ${ }^{17}$ Inhaled steroid is not usually enclosed in the routine management of COPD, even by those physicians who include asthma under COPD. Thus, patients with asthma, inadvertently labeled with the diagnosis of COPD, are likely to be denied inhaled steroids. Asthma is a chronic inflammatory disorder of the airways and one cannot think of managing chronic asthma without inhaled steroids. Thus, in any breathless patient clinical evidence of asthma should be looked for. It may really turn out to be a therapeutically miracle for the patient.

\section{REFERENCES}

1. Sears MR. Descriptive epidemiology of asthma. Lancet 1997; 350 (suppl 11): 14

2. Behera D. Bronchial Asthma. New Delhi: Jaypee Brothers, 2000: 2 .

3. Taylor AJN. Asthma. In: Warrel DA, Cox TM, Firth JD, Benj Jr EJ, eds. Oxford Textbook of Medicine. $4^{\text {th }}$ Edition. Oxford: Oxford University Press, 2003: 2.1335.

4. Becklake MR, Ernst P. Environmental factors. Lancet 1997; 350 (suppl 11): 1013.
5. Holgate ST. The cellular and mediator basis of asthma in relation to natural history. Lancet 1997; 350 (suppl 11): 59.

6. Pandey MR, Basent B, Neupane RP. Chronic Bronchitis and cor pulmonale in Nepal. A study report 1988: 20-21.

7. Bhattarai MD, Regmi PR, Pokhrel DC, Shrestha JK. Disease pattern of the patients attending medicine unit of a free mobile specialist health camp. J Nep Med Assoc 1998; 37, 126: 502-5.

8. Singh DL, Manandhar K, Bhattarai MD, Pokhrel DC, Khanal H, Gurung SB. Study of the patients attending the Department of Medicine, Bir Hospital in the year 2051. Proc Bir Hosp 1995: 71-74.

9. Bhattarai MD. Asthma mistaken for chronic obstructive pulmonary disease. Lancet 2003; 361: 1914-15.

10. Jatulis DE, Meng Y, Elashoff RM. Preventive pharmacologic therapy among asthmatics: five years after publication of guidelines. Ann Allergy Asthma Immunol 1998; 81: 82-88.

11. Enright PL, McClelland RL, Newman AB, Gottlieb DJ, Lebowitz MD, and for the Cardiovascular Health Study Research Group. Underdiagnosis and undertreatment of asthma in the elderly. Chest 1999; 116: 603-13.

12. Sin DD, Tu JV. Underuse of inhaled steroid therapy in elderly patients with asthma. Chest 2001; 119: 720-25.

13. Nepal M. Study of baseline and postbronchodilator pulmonary function test and changes after treatment with two weeks of systemic steroid in presumed COPD cases. Thesis undertaken under the guidance of M D Bhattarai for MD degree, Tribhuvan University, Kathmandu, Nepal, 2003.

14. Paudel VP, Singh DL, Bhattarai MD. Clinical profile, pulmonary function tests and arterial blood gas analysis of patients with chronic cor-pulmonale. Post-graduate Medical Journal of Nepal (PMJN) 2002, 3

15. Honig EG, Ingram RH Jr. Chronic bronchitis, emphysema, and airways obstruction. In: Braunwald E, Fauci AS, Kasper DL, Hauser SL, Longo DL, Jameson JL, eds. Harrison's Principles of Internal Medicine. $15^{\text {th }}$ edition. New York: McGraw-Hill, 2001: 1491.

16. Weiss ST, Speizer FE. Epidemiology and natural history. In: Weiss EB, Stein M, eds. Bronchial Asthma - Mechanisms and Therapeutics. Third Edition. Boston: Little, Brown and Company, 1993: 15

17. Bhattarai MD. Why not call chronic obstructive pulmonary disease (COPD) simply obstructive chronic bronchitis and emphysema (OCBE)? Proceedings of the Royal College of Physicians of Edinburgh 2000; 30: 265. 